\title{
Requirement Elicitation Techniques for Software Projects in Ukrainian IT: An Exploratory Study
}

\author{
Denys Gobov \\ National Technical University of Ukraine \\ "Igor Sikorsky Kyiv Polytechnic Institute", \\ 37, Prosp. Peremohy, Kyiv, Ukraine \\ Email: d.gobov@kpi.ua
}

\author{
Inna Huchenko \\ National Aviation University, \\ 1, Liubomyra Huzara ave., Kyiv, Ukraine \\ Email: inna.guchenko@hotmail.com
}

\begin{abstract}
Elicitation is a core business analysis/requirement engineering activity that provides inputs for another one: analysis, specification, confirmation, management. There is a significant number of specialized techniques that are used for requirement elicitation. The selection of the appropriate techniques considerably influences a project plan and success of a change as a whole. This paper is intended to analyse the industrial standards and experience of business analysts and requirement engineers in part of elicitation activities. We conducted a survey study involving 328 specialists from Ukrainian IT companies and a series of interviews with experts to interpret survey results. Furthermore, this paper provides the guideline in selecting a particular elicitation technique with respect to the type of project and situation.
\end{abstract}

\section{INTRODUCTION}

B USINESS analysis is the practice of providing opportunities for change in the context of an enterprise's work by identifying needs and recommending solutions that bring value to stakeholders [1]. This discipline extends the scope of requirement engineering activities and area of their application [2], [3]. There are different views on the set of business analysis tasks depending on project methodology and solution type. Overall all business analysis tasks can be grouped into six knowledge areas: Business Analysis Planning and Monitoring, Elicitation and Collaboration, Requirements Life Cycle Management, Strategy Analysis, Requirements Analysis and Design Definition, and Solution Evaluation. If business analysis provides a basis for all future activities of development and testing, requirement elicitation provides a basis for future activities with requirements: specification and modelling, analysis, verification and validation, prioritization, maintaining, etc. So failure in this are lead to significant issues with project outcomes. According to [4] 39\% of respondents recognized errors in the stage of requirements gathering one of the most influential factors that led to the failure of software development projects. Other industry studies reach the same conclusion [5], [6]. Elicitation is not an isolated activity. Information is gathering while performing any task that includes interaction with stakeholders and while the business analyst is analysing existent data. Elicitation may trigger additional elicitation for details to fill in gaps or

This work was supported by IIBA Ukraine Chapter increase understanding. Elicitation activities can be divided into three tasks: prepare for elicitation, conduct elicitation, and confirm elicitation results [7]. During preparing a business analyst should understand the scope of elicitation and select an appropriate set of elicitation techniques. Choosing the right techniques and ensuring each technique is performed correctly is extremely important to the success of the elicitation activity. The best practices and recommendation regarding elicitation techniques are defined in international standards [8], industrial bodies of knowledge [1], [9], [10], International empirical studies [11], [12].

There is a significant number of elicitation techniques that have proven themselves in practice and are recommended in the sources mentioned above. Each of them has its advantages and limitations, requires stakeholders' involvement or study materials availability. As a part of business analysis approach and business analysis activities plan a business analyst needs to decide which techniques are best suited for a particular project. Usually multiple techniques are used for elicitation. Decision about the set of techniques depends on time and cost constraints, the types of business analysis information sources and their accessibility, the culture of the company, and the desired outcomes [1]. If elicitation is built based on the collaborative approach the needs of the stakeholders, their availability and location have to be taken into account.

This study was conducted to analyse the current preferences of business analysts and requirement engineers regarding elicitation selection approach for software development projects. We also wished to define attributes of project contexts which influence the probability of choosing a particular elicitation technique. We also wanted to take into account the specifics of distributed and collocated teams to determine the applicable such techniques, which is especially important in the context of the widespread use of outsourcing services and work with international companies. Our approach was to study the experience of practicing specialists from Ukrainian and international companies with branches in Ukraine involved in requirement gathering for IT projects. The main research method was a survey and statistical analysis.

The paper is structured as follows. Section II contains a review of the related works on elicitation activities and survey study regarding requirement engineering and business 
analysis. In Section III we provide background information on requirements elicitation techniques, collected from industrial bodies of knowledge and study materials prepared by leading international organization in business analysis area. The section III is devoted to the structure of the questionnaire along with the selection of characteristics of the IT project. Also, it contains the survey results and dependencies identified based on the statistical analysis of received data. Section IV concludes the paper with discussion of the findings of our study and future work.

\section{RELATED WORKS}

The most of the related works is focused on analysis of elicitation activities and elicitation techniques in particular. Dieste and Juristo [13] performed a systematic review on requirements elicitation techniques based on 26 empirical studies published till the year 2005. They aggregated the results in terms of five guidelines for RE practitioners. Wong at. all [14] perform systematic review on software requirement elicitation activities based on 35 articles and defined that most of the contributions were focused on the "Identify Requirements" activity (91\%) and other activities are poorly covered: "Acquire knowledge" (17\%),"Identify sources" (4\%), "Defining technique" (9\%), "Document" (9\%) and "Refine requirements" (4\%). Pacheco and Garcia [15] performed an systematic review on stakeholder identification during requirements elicitation based on 47 primary studies dated from 1984 to 2011. They found that identified approaches are not able to cover all aspects of stakeholder identification during requirements elicitation. In [16] authors noticed that there is need to replicate studies in different contexts wherein existing requirement engineers' interventions were evaluated and implemented in practice. It confirms that most of the case studies involve practitioners as participants, there is a need to work more closely with practitioners. Several studies assess effectiveness of elicitation techniques in the context of particular project. Hafsa at all. [17] performed systematic study on elicitation techniques in mobile application development project. Based on the analysis of 36 selected articles 22 requirement gathering methods and 8 different categories of requirement gathering challenges for mobile application were identified. In [18] systematic literature review was performed for elicitation techniques for Internet of things application requirement. The interview and prototyping were identified as a most elicitation techniques used between 2012 and 2018, data mining was mentioned as a technique that complements traditional elicitation techniques in order to mitigate the effects of insufficient requirements elicitation. In [19] authors defined several factors that can influence elicitation technique selection. This study selected five practitioners as informants from Yemen's companies and government agency. Dieste and Juristo [20] proposed a framework that can help requirements engineers to select the most adequate elicitation techniques. The set of attributes are relevant to the context of the elicitation process and influence the selection of one or other technique were discovered. Two groups of students were involved in experiment, practitioners did not took part in experiment. Author noticed that there results were not generalizable and should checked with other larger samples. Wong and Mauricio [21] defined a set of factors that influenced each activity of the requirements elicitation process and, consequently, the quality: learning capacity, negotiation capacity, permanent staff, perceived utility, confidence, stress, and semi-autonomous. An empirical study was carried out on 182 respondents from software development companies in Peru. The main limitations of the empirical studies mentioned above are limited number of participants and low practitioners' involvement. During last years a practice of dispersed team and outsourcing/outstuffing services model have become rather rule then exception, but influence of these factors the elicitation has not been analyzed. Survey preparation contained three steps:

- Practical guidelines and bodies of knowledge analysis to define a long list of elicitation techniques.

- It industry trend reports analysis to define an attributes that characterize the context of software projects.

- Preliminary interviews with five business analysts from Ukrainian IT companies to check a list of techniques and project characteristics.

The following sources were used for creating elicitation technique long list: "A Guide to the Business Analysis Body of Knowledge" (BABOK) from the International Insitute of Business Analysis (IIBA), "The PMI Guide to Business Analysis" from the Project Managememnt Institue (PMI), a study guide from the International Requirement Engineering Board (IREB) "Requirements engineering fundamentals" and book "Business Analysis" from British Computer Society (BCS). The analysis of the contents of these sources gives us a set of 17 requirements elicitation. In some cases the different names are used for the one technique, variants are included in the result tables per each sources if it is applicable. Short descriptions of these 17 techniques are given below.

Benchmarking and Market Analysis. Benchmark studies are conducted to compare organizational practices against the best-in-class practices. Market analysis involves researching customers in order to determine the products and services that they need or want, the factors that influence their decisions to purchase, and the competitors that exist in the market [1]. Brainstorming. Brainstorming is an elicitation technique that can be used to identify a list of ideas in a short period of time (e.g., a list of risks, stakeholders, or potential solution options). Brainstorming is conducted in a group environment and is led by a facilitator. A topic or issue is presented and the group is asked to generate as many ideas as possible about the topic [1], [9].

Analysis of business rules involves capturing business rules from sources, expressing them clearly, validating them with stakeholders, refining them to best align with business goals, and organizing them so they can be effectively managed and reused. Sources of business rules may be explicit (for example, documented business policies, regulations, or contracts) or tacit (for example, undocumented stakeholder know-how, gen- 
TABLE I

REQUIREMENTS ELICITATIONS TECHNIQUES IN MAIN INDUSTRIAL GUIDELINES

\begin{tabular}{|c|c|c|c|c|}
\hline Technique Name & IIBA & PMI & BCS & IREB \\
\hline Benchmarking and Market Analysis & + & + & & + (Analogy techniques) \\
\hline Brainstorming & + & + & $\begin{array}{l}+(\text { Brainwriting, Round } \\
\text { robin) }\end{array}$ & $\begin{array}{l}+ \text { (Brainstorming para- } \\
\text { dox })\end{array}$ \\
\hline Business Rules Analysis & + & $\begin{array}{l}+ \text { (as a part of document } \\
\text { analysis })\end{array}$ & & $\begin{array}{l}+ \text { (as a part of document } \\
\text { analysis) }\end{array}$ \\
\hline Collaborative games & $\begin{array}{l}+ \text { (Product box, Affinity } \\
\text { map, Fishbowl) }\end{array}$ & $\begin{array}{l}\text { +(Product box, Speedboat, } \\
\text { Spider web) }\end{array}$ & $\begin{array}{l}+ \text { (Sticky (post-it) note } \\
\text { exercises, Smaller 'break- } \\
\text { out' or 'syndicate' groups) }\end{array}$ & $+($ Change of perspective $)$ \\
\hline Concept Modelling & + & & & \\
\hline Data Mining & + & & & \\
\hline Data Modelling & + & & & \\
\hline Document Analysis & + & + & + & $\begin{array}{l}+(\text { System archaeology, } \\
\text { Perspective-based } \\
\text { reading })\end{array}$ \\
\hline Workshops \& Focus Groups & + & + & + & + \\
\hline Interface Analysis & + & & & \\
\hline Interview & + & + & + & + \\
\hline Mind Mapping & + & & + & + \\
\hline Observation & + & + & $\begin{array}{l}+ \text { (Activity sampling, Spe- } \\
\text { cial purpose records) }\end{array}$ & $\begin{array}{l}+(\text { Field observation, Ap- } \\
\text { prenticing) }\end{array}$ \\
\hline Process Analysis/ Modelling & + & + & $+($ Scenario $)$ & $\begin{array}{l}+ \text { (Modelling action se- } \\
\text { quences) }\end{array}$ \\
\hline Prototyping & + & + & & + \\
\hline Survey or Questionnaire & + & + & + & + \\
\hline
\end{tabular}

erally accepted business practices, or norms of the corporate culture) [1].

Collaborative games are a collection of elicitation techniques that foster collaboration, innovation, and creativity to achieve the goal of the elicitation activity. Collaborative games use game play to encourage team participation and enhance engagement.The games are used to help the participants share their knowledge and experience on a given topic, identify hidden assumptions, and explore that knowledge in ways that may not occur during the course of normal interactions. The shared experience of the collaborative game encourages people with different perspectives on a topic to work together in order to better understand an issue and develop a shared model of the problem or of potential solutions. Many collaborative games can be used to understand the perspectives of various stakeholder groups [1], [9].

A concept model is used to organize the business vocabulary needed to consistently and thoroughly communicate the knowledge of a domain. Concept models put a premium on high-quality, designin dependent definitions that are free of data or implementation biases. Concept models also emphasize rich vocabulary. As an elicitation technique is used to identify key terms and ideas of importance and define the relationships between them [1].

Data mining is an analytic process that examines large amounts of data from different perspectives and summarizes the data in such a way that useful patterns and relationships are discovered. Data mining can be utilized in either supervised or unsupervised investigations. In a supervised investigation, users can pose a question and expect an answer that can drive their decision making. An unsupervised investigation is a pure pattern discovery exercise where patterns are allowed to emerge, and then considered for applicability to business decisions [1].

A data model describes the entities, classes or data objects relevant to a domain, the attributes that are used to describe them, and the relationships among them to provide a common set of semantics for analysis and implementation. Data modelling is used to understand entity relationships during elicitation. Most guidelines [9], [10], [22] do not recognize it as a core elicitation technique.

Document analysis is used to elicit business analysis information, including contextual understanding and requirements, by examining available materials that describe either the business environment or existing organizational assets. Document analysis may be used to gather background information in order to understand the context of a business need, or it may include researching existing solutions to validate how those solutions are currently implemented. Document analysis may also be used to validate findings from other elicitation efforts such as interviews and observations. [PMI, BABOK] Workshops use a structured meeting led by a skilled, neutral facilitator and a carefully selected group of stakeholders to collaborate and work toward a stated objective. Focus groups 
bring together prequalified stakeholders and subject matter experts (SMEs) to learn about their expectations and attitudes about a proposed solution. Focus groups provide an opportunity to obtain feedback directly from customers and/or end users [1], [9].

Interface analysis is used to identify where, what, why, when, how, and for whom information is exchanged between solution components or across solution boundaries. . Most solutions require one or more interfaces to exchange information with other solution components, organizational units, or business processes [1].

An interview is a formal or informal approach used to elicit information from stakeholders. It is performed by asking prepared and/or spontaneous questions and documenting the responses. Interviews are often conducted on an individual basis between an interviewer and an interviewee, but they may also involve multiple interviewers and/ or multiple interviewees. Questions that arise during the conversation can be discussed immediately, and the requirements engineer may uncover subconscious requirements through clever questions [9], [10].

Mind Mapping is used to generate many ideas from a group of stakeholders in a short period, and to organize and prioritize those ideas [1].

Observation is an elicitation technique that provides a direct way of obtaining information about how a process is performed or a product is used by viewing individuals in their own environment performing their jobs or tasks. This technique is helpful when domain specialists are unable to spend the time needed to share their expertise with the requirements engineer, or are unable to express and denote their knowledge [1], [10].

Process Analysis is used to understand current processes and to identify opportunities for improvement in those processes. Process Modelling is a standardized graphical model used to show how work is carried out and is a foundation for process analysis [1].

Prototyping is used to elicit and validate stakeholder needs through an iterative process that creates a model or design of requirements. It is also used to optimize user experience, to evaluate design options, and as a basis for development of the final business solution. This technique helps the business users to visualise the solution and hence increases understanding about the system requirements [1], [22].

Questionnaires and surveys are written sets of questions designed to quickly accumulate information from a large number of respondents. Survey respondents can represent a diverse population and are often dispersed over a wide geographical area. As a form of elicitation, this technique has the benefit of reaching a large group of people for a relatively small cost [9], [22].

\section{SURVEY STUDY}

\section{A. Questionnaire design}

The literature review has shown that many researches have been conducted for identifying common patterns and problems in IT business analysis and requirements elicitation in particular. However, after studying of the existing questionnaries developed for international surveys, we realized the necessity of adjusting them to Ukrainian IT companies' specifics. It was decided to take questions' basis from NaPIRE initiative [12] and rework it with respect to mentioned above sources such as [1], [8], [9], [10]. Survey items were carefully written using the business analysis vocabulary, mostly from BABOK. Types of questions used for the questionnaire are open-ended, closed-ended (multiple and single choice) and Likert scale.

Total number of questions is 43. After several rounds of internal peer reviews, the questionnaire was given for validation by business analysis experts from Ukrainian IT industry leaders. Among comments received as the first feedbacks, there were remarks about time needed for answering the questions (it took too long to complete the questionnaire) and complexity of some terms that might cause the clarity problems for young professionals. After recommended improvements were done, cognitive interviews were conducted with 10 potential respondents to determine how they interpret the terms, questions and answer options. After that step questionnaire was ready for distribution.

Our target group of respondents was IT professionals from Ukraine, mainly business analysts but also other roles involved in business analysis or requirements engineering activities. Overall number of survey participants is 328. English and Ukrainian languages were used for questionnaires. The questionnaire itself was created using Google forms and link to it was shared in the local Business Analysis communities, professional and social networks, and via personal contacts in TOP 10 Ukrainian IT companies. Answers were collected during one month. After that, data were merged and coded for further analysis. The following questions' categories were included into the questionnaire:

- Q1: General Information.

- Q2: Requirements Elicitation and Collaboration.

- Q3: Requirements Analysis and Design.

- Q4: Requirements Verification and Validation.

- Q5: Requirements Management.

- Q6: Attitude to the Business Analysis in the project.

- Q7: Problems, Causes and Effects.

In given article we focus on Elicitation and Collaboration topic in the context of general information questions about respondents' background.

Q1: General Information. Questions in this section were intended to give the context such as:

- Project size.

- Main industrial sector of the current project. Set of industrial sectors was taken from [12] and reworked with respect to domain areas within which services are offered by most of the Ukrainian IT Companies.

- Company type: IT or non-IT. For IT companies the separation was made among Outstaff, Outsource and

- Product companies.

- Company size. 
- Class of systems or services such as business, embedded, scientific software etc.

- Team distribution (co-located or distributed).

- Role in the Project

- Experience in business analyst (BA)/requirements engineer (RE) role

- Certifications

- Way of working in the project (adaptive vs predictive)

- Project category for most of the participant's projects (e.g. greenfield engineering)

- BA/RE activities which respondent is usually involved in.

Q2: Requirements Elicitation and Collaboration. Within given questions category we were interested in elicitation sources, techniques and project role having primary responsibility for the solution requirements (functional, non-functional requirements) elicitation on the respondent's ongoing project.

The following types of elicitation sources were considered: collaborative (relies on stakeholders' expertise and judgements); experiments, e.g. observational studies, proofs of concept, and prototypes; research, i.e. information from materials or sources that are not directly known by stakeholder. 16 elicitation techniques were proposed as answer options with ability to select as many as needed for reflecting the full range used by respondents. Typical cases were taken as the base for the requirements elicitation responsibility topic and resulted in the following options: Business Analyst/Requirements Engineer, Product Owner/Business Analyst, Product Owner/Product Manager, Project Lead/Project Manager and Solution Architect. Also, we considered the case when in fact nobody has the primary responsibility.

\section{B. Survey results. Participants Background}

Figures 1-6 show the typical environment for the Ukrainian business analyst in terms of company, team, project role and type, experience etc. For the initial analysis the Pareto sorted histogram with cumulative curve was used.

The numbers in each figure allow to make the following observations:

- $41 \%$ of respondents are working in the project groups up to 15 members. Less than $13 \%$ are participating in projects with over 100 people (Fig. 1).

- $49 \%$ of the survey participants are employed in IT outsource companies while IT outstaff, product and inhouse development is represented in almost the same amount within left $51 \%$ of respondents (Fig. 2).

- About $80 \%$ of respondents are specialists with experience from 1 to 5 years, mode value is 1-3 years (Fig. 3).

- Predictive/rather predictive methodologies (e.g. RUP, Waterfall) are used in less than $15 \%$ of the projects (Fig. 4).

- Most of the participants have a Business Analyst role on the project, however, quite often this role is combined with a product ownership (Fig. 5).

- The TOP 3 popular industry sectors are Finance/Banking, e-Commerce/Retail and Healthcare/Pharmaceuticals. Variety of domains is represented in Fig. 6.

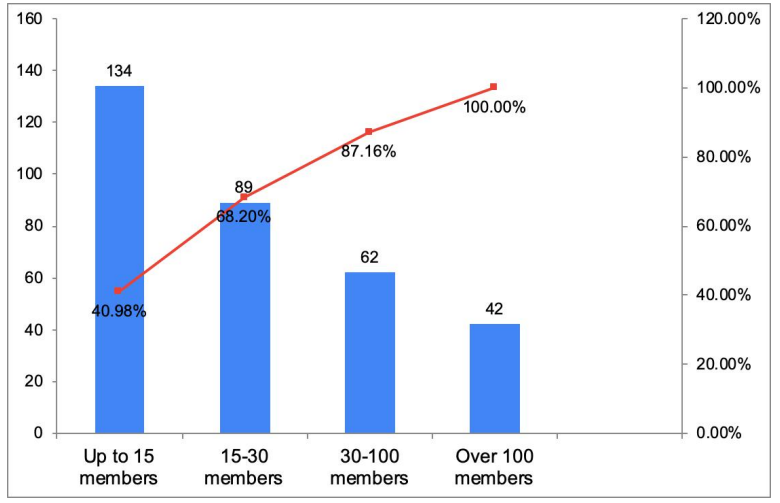

Fig. 1. Project size

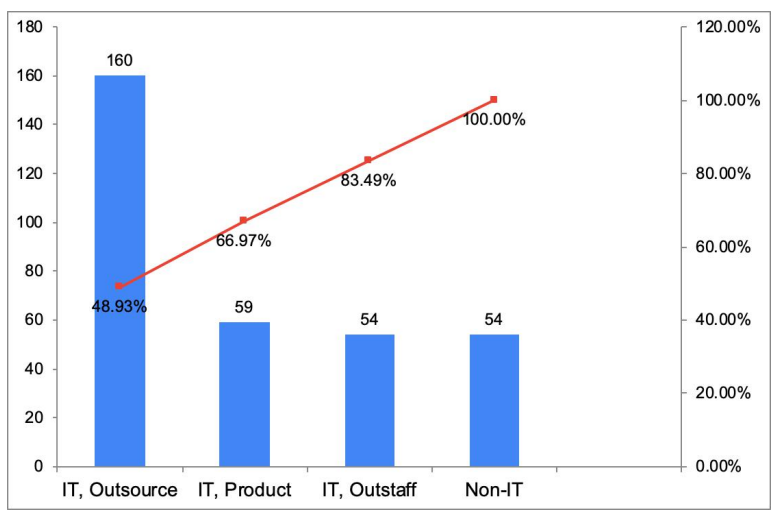

Fig. 2. Company Type

- Only $13 \%$ of respondents have certifications and $5 \%$ have more than 1 certificate.

Thus, the typical portrait of Ukrainian IT Business Analyst could be described using the observations above.

\section{Survey results. Elicitation techniques usage}

The most used elicitation techniques are shown in Fig. 7. Participants were allowed to select multiple techniques. Regardless the context in which the Ukrainian Business An-

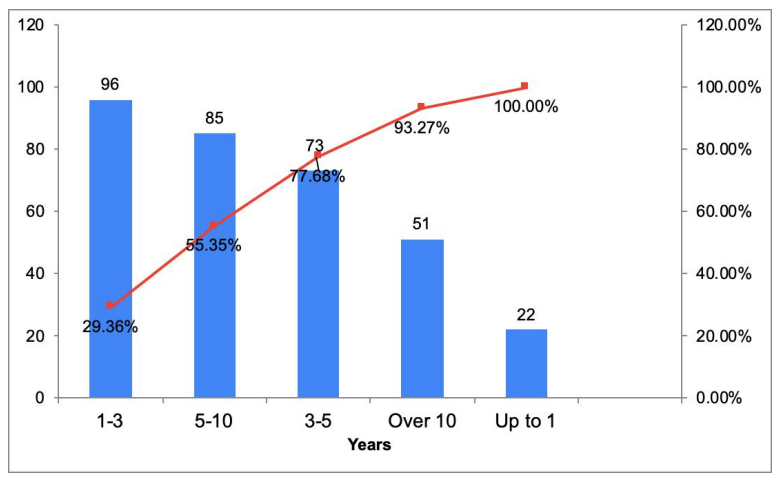

Fig. 3. Experience in BA/RE role 


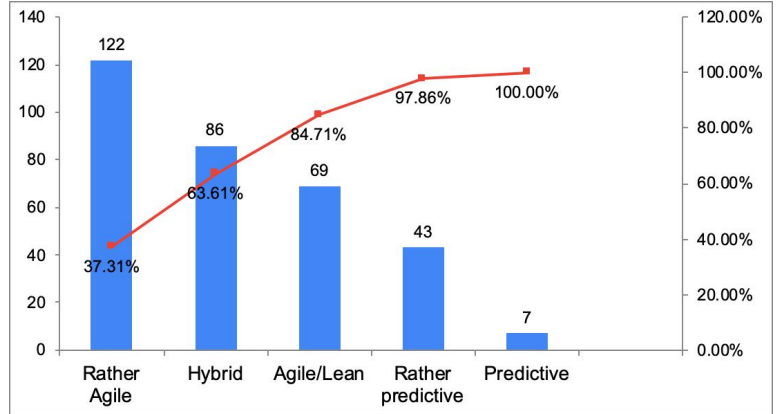

Fig. 4. Ways of working in the project

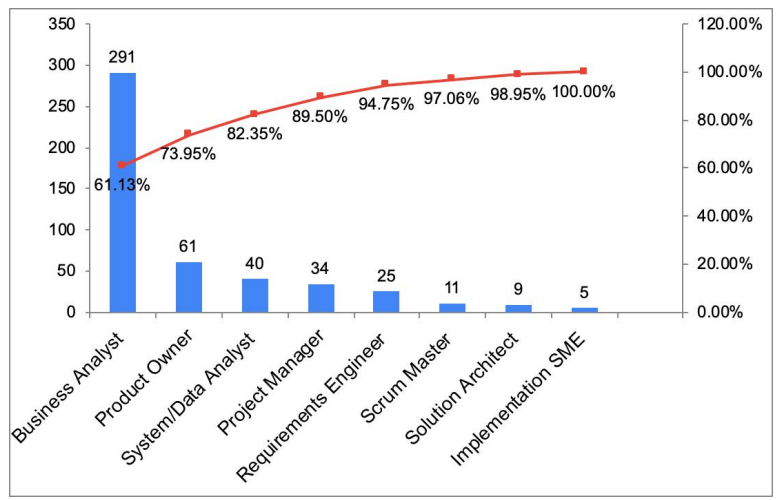

Fig. 5. Role in the project

alyst is working, we may see that the following elicitation techniques are the most popular (Fig. 7):

- Interview

- Document analysis

- Interface analysis

- Brainstorming

- Prototyping

- Process analysis/Process modelling

The rare techniques are Collaborative Games, Design Thinking and Data Mining.

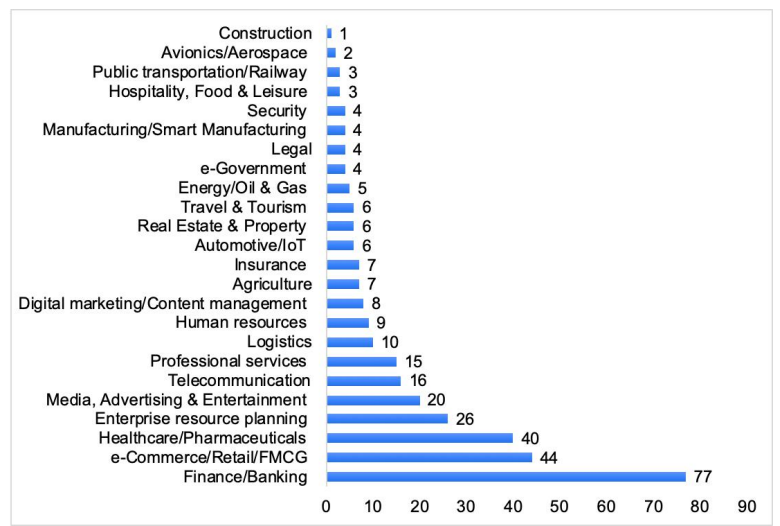

Fig. 6. Industrial sector

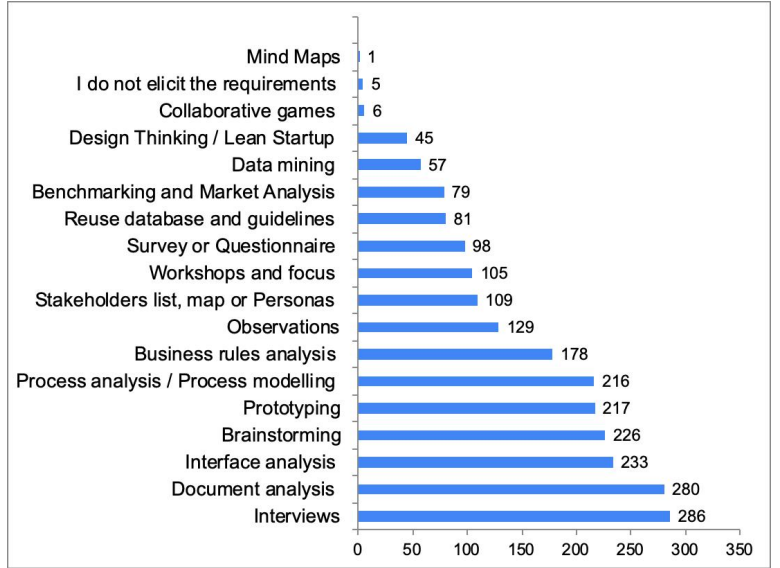

Fig. 7. Elicitation techniques popularity

Most of the respondents use such elicitation sources as collaborative (stakeholders' expertise) and research, 96\% and $62 \%$ respectively. Only $49 \%$ of participants selected experiments as one of the options. The last fact could be explained by general complexity of observational studies and prototypes in the terms of efforts and time.

The elicitation responsibility is taken by Business Analyst/Requirements Engineer in $44 \%$ of cases, Business Analyst/Product Owner - 38\%, Product Owner/Product Manager - $10 \%$, left $8 \%$ are shared between Project Manager and Solution Architect roles.

During the questionnaire results analysis, the significant difference in the usage of several techniques from particular background perspective was noticed. It was decided to check each "background factor-elicitation technique" pair for association. The Chi-Square test of independence, commonly used for testing relationships between categorical variables, was applied to examine the differences within single dependent sample (population). Set of hypotheses about the association between particular factor and technique usage was developed. The example of null and alternative hypothesis is:

$\mathrm{HO}$ : There is no association between BA/RE experience and Workshops elicitation technique usage.

$\mathrm{H} 1$ : There is an association between $\mathrm{BA} / \mathrm{RE}$ experience and Workshops elicitation technique usage.

Chi-Square test has a number of assumptions critical for results reliability. These assumptions were checked and confirmed on the data preparation stage, namely:

- The data are randomly drawn from a population. This statement is confirmed by the method used for questionnaire distribution.

- The values in the cells are considered adequate when expected counts are not less than 5 and there are no cells with zero count [23], [24].

- The sample size is large enough. The minimum recommended size varies from 20 to 50 in different sources. This statement is also true as respondents' number for the study is 325 (filtered from initial 328). 
- The variables under consideration must be mutually exclusive, i.e. no item shall be counted twice. For study purposes, data were transformed in such a way that for every Participant ID usage of the particular elicitation technique was set to " 1 " if technique was selected and " 0 " if wasn't, i.e. the observations were classified into mutually exclusive classes.

After calculation of P-Value, which should be less than 0.05 considering 0,95 confidence level, the conclusion about statistical significance was made for the following factorelicitation technique pairs:

- Company Type - Documentation Analysis (Fig. 8). Given elicitation technique is more frequently used in IT Outsourcing companies. The common problem for outsourcing is lack of the project team familiarity with Customer's already existing systems and/or business. Thus, studying the existing documentation is the very first step for the $\mathrm{BA} / \mathrm{RE}$.

- Company Type - Process Analysis/Process Modelling (Fig. 9). As it could be seen from the bar chart, the technique is a must use in non-IT, inhouse development. Also, in IT outsource it is used wider than in outstaff or product development.

- Methodology - Design Thinking/Lean Startup (Fig. 10). As survey shows, design thinking is not a popular technique and is used mostly in agile development.

- Experience - Workshops/Focus Groups (Fig. 11). The more experience BA/RE has, the more often given technique is applied.

- Experience - Interviews (Fig. 12). Less usage of nterviews is observed for the young specialists with experience less than 1 year and for those over 10 years.

- Experience - Prototyping (Fig. 13). Respondents with experience over 3 years see the obvious benefit in prototyping and, thus, use this technique frequently.

- Experience - Stakeholders list, map or Personas (Fig. 14). The more experience, the less is the gap between use/no use for mentioned set of techniques.

P-Value for each pair having statistically significant relationship is stated under corresponding graphs in Fig. 8 - Fig. 14.

Also, the statistically significant relationships were identified for the Elicitation Responsibility background factor and the techniques below:

- Process Analysis/Process Modelling, $\mathrm{p}=0,017$

- Prototyping, $\mathrm{p}=0,018$

- Reuse database and guidelines, $\mathrm{p}=0,039$

- Design Thinking/Lean Startup, $p=0,049$

Corresponding graphs are not included here due to space limitations.

First two techniques are used often if responsibility for the elicitation belongs to Business Analyst/Requirements Engineer and/or Product Owner. As for Design Thinking and Reuse database, the situation is quite opposite, - these techniques are rarely applied by roles mentioned above.

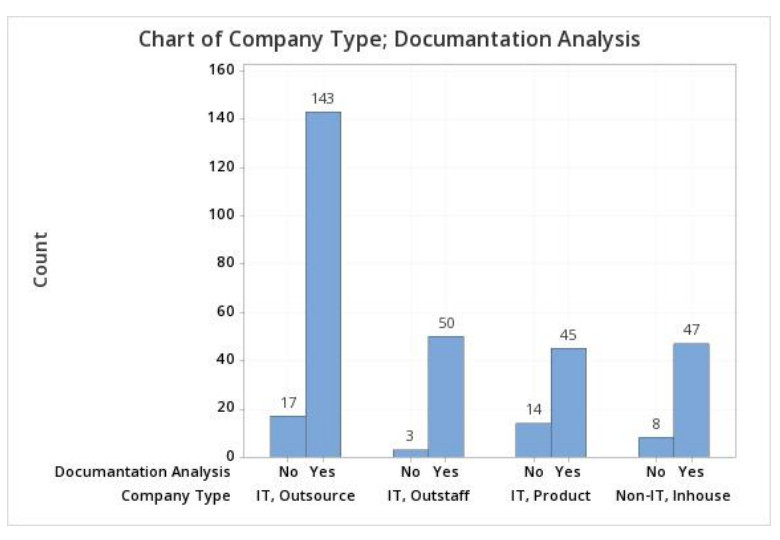

Fig. 8. Relationship between Company type and Documentation Analysis technique usage, $\mathbf{p}=\mathbf{0 , 0 2 8}$ (Chi-Square Test)

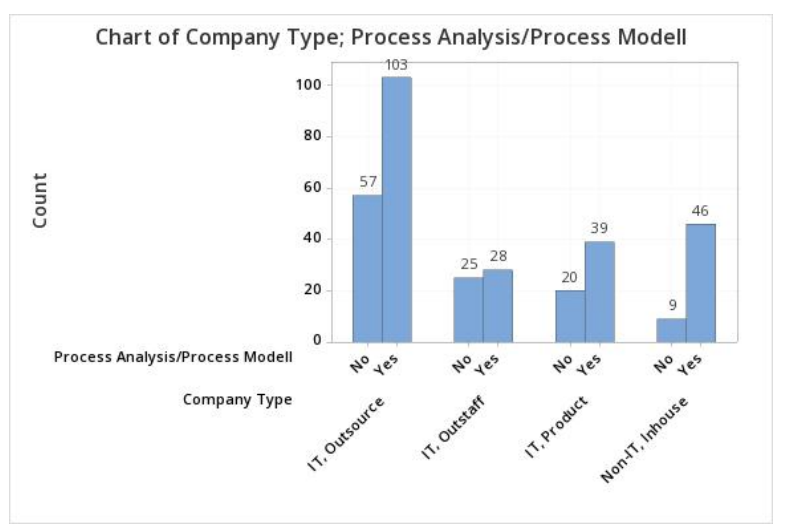

Fig. 9. Relationship between Company type and Process Analysis/ Process Modelling technique usage, $\mathbf{p}=\mathbf{0 , 0 0 5}$ (Chi-Square Test)

The hypotheses about relation between certificates and experience, company size and responsible for the requirements elicitation, team distribution and particular technique usage weren't confirmed by Chi-Square Test results.

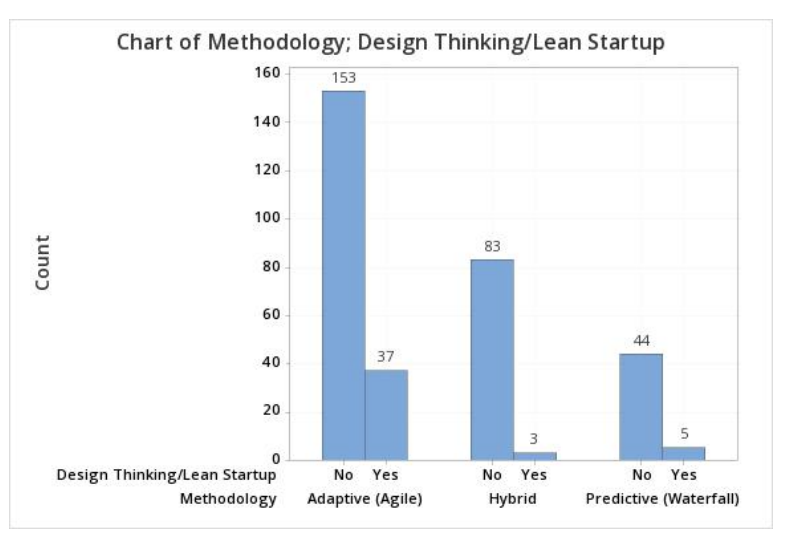

Fig. 10. Relationship between Methodology and Design Thinking/Lean Startup technique usage, $\mathbf{p}=\mathbf{0 , 0 0 1}$ (Chi-Square Test) 


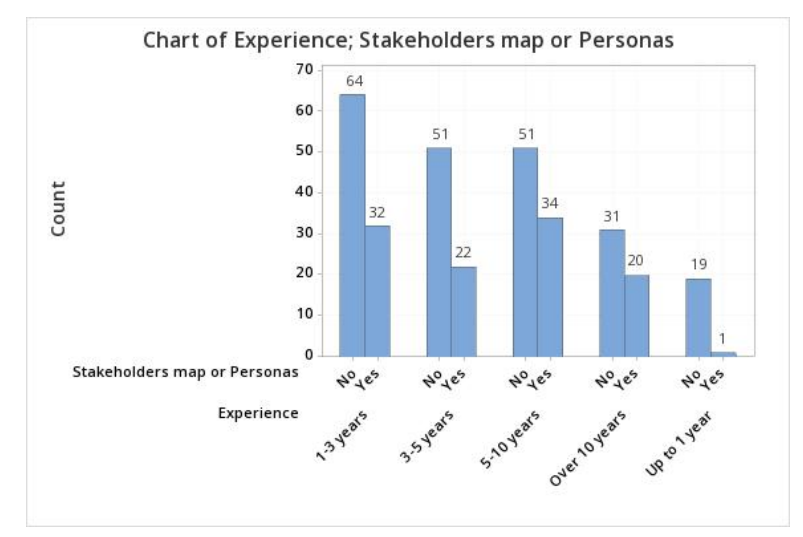

Fig. 14. Relationship between Experience and Stakeholders map or Personas, $\mathbf{p}=\mathbf{0 , 0 1 4}$ (Chi-Square Test)

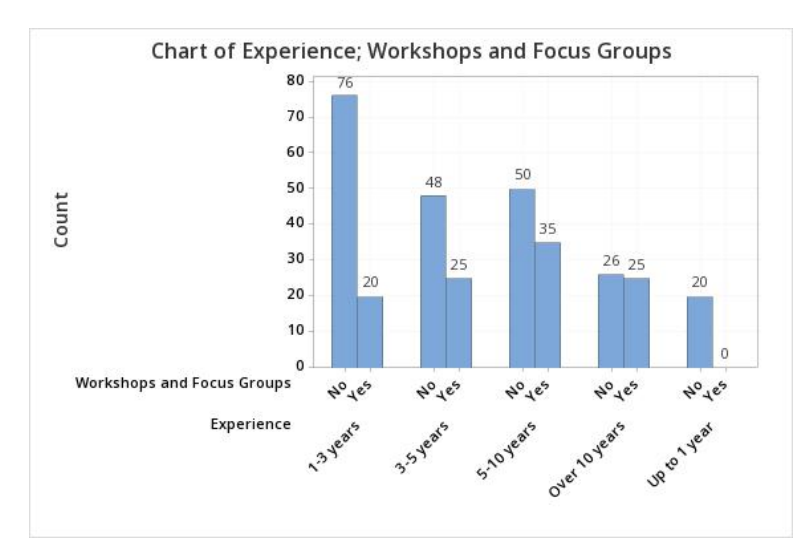

Fig. 11. Relationship between Experience and Workshops/Focus Groups technique usage, $\mathbf{p}=\mathbf{0 , 0 0 1}$ (Chi-Square Test)

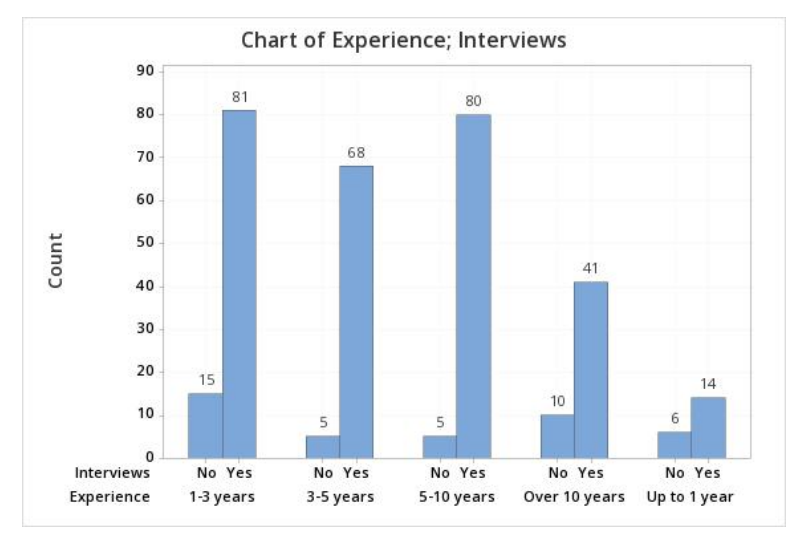

Fig. 12. Relationship between Experience and Interviews technique usage, p $=\mathbf{0 , 0 0 8}($ Chi-Square Test $)$

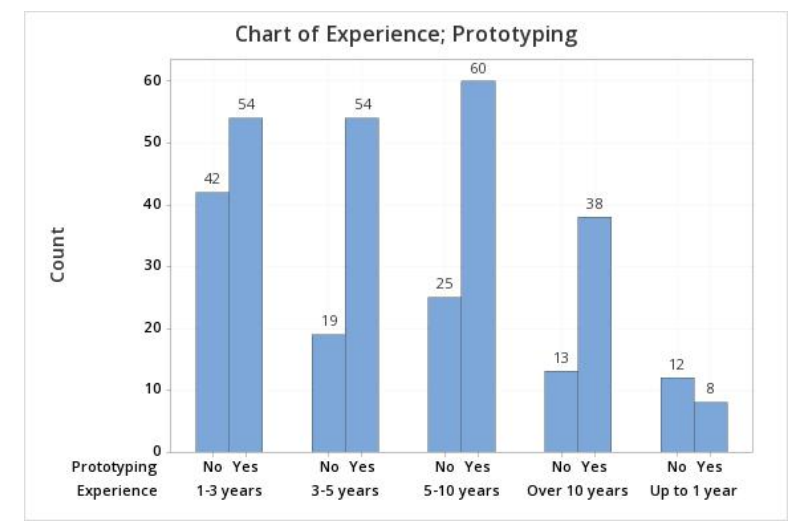

Fig. 13. Relationship between Experience and Prototyping technique usage, $\mathbf{p}=\mathbf{0 , 0 0 7}$ (Chi-Square Test) 


\section{CONCLUSION}

A survey study dedicated to the analysis of current state and selection of requirements elicitation techniques in different software project contexts has been conducted. The survey structure was built based on the worldwide known industrial standards. Attributes of project context were established to analyze influence the requirement elicitation techniques. The survey was conducted among practitioners from the Ukrainian IT and non-IT companies, 328 specialists (mainly business analysts and product owners) took part in the survey. The seven most used elicitation techniques were defined: Interview (used by $89 \%$ of respondents), Document analysis (87\%), Interface analysis (72\%), Brainstorming (70\%), Prototyping(67\%), Process analysis/Process modelling (67\%). This result can be used as guidance or practical advice for selection a core set of elicitation techniques. The Chi-Square Test (Cross Tabulation) was applied to examine the relationships between project context and requirement elicitation technique usage. The statistically significant relationship were identified for the following project context attributes and elicitation techniques: Company type - Document analysis, Process Analysis/Process Modelling; Elicitation responsibility - Process Analysis/Process Modelling, Prototyping, Reuse database and guidelines, Design Thinking/Lean Startup; Methodology - Design Thinking/Lean Startup; Experience of business analyst - Workshops/Focus Groups, Interviews, Prototyping. The hypotheses about relation between certificates and experience, company size and responsible for the requirements elicitation, team distribution and particular technique usage were not confirmed by Chi-Square Test results. These dependencies can be used as guidance for selection supportive techniques or adjusting set of core elicitation techniques. Our study had several limitations. The list of techniques included in the survey is not exhaustive. Elicitation techniques may be applied alternatively or in conjunction with other techniques. Due to specific of project context business analysts are encouraged to modify techniques or engineer new ones. The survey result gathering via google survey engine and was intended to be anonymous (requiring personal data is problematic on legal and ethical grounds), therefore we cannot prove that respondents provided true information about project context and used elicitation techniques. Taking into account that the survey was limited to one country only, its results cannot extrapolated for worldwide software industry (even though IT industry in Ukraine is integrated in international environments, especially outsourcing and outstaffing companies, whose employees were the majority of respondents $(65 \%)$. Several directions for future research can be considered. Other business analysis' tasks can be analyzed to define dependencies and recommendation regarding selection techniques for requirement specification and modelling, validation and verification. The factor analysis can be used to identify and assess variability among observed, correlated variables (project context attributes, and business analysis techniques).

\section{REFERENCES}

[1] International Institute of Business Analysis, "A guide to the business analysis body of knowledge (BABOK Guide)" ver. 3, IIBA, 2015.

[2] J. Rubenss, "Business analysis and requirements engineering: the same, only different?" Requirements Engineering vol. 12(2), 2007, pp. 121123, dx.doi.org/10.1007/s00766-007-0043-3

[3] M. Aoyama, "Bridging the requirements engineering and business analysis toward a unified knowledge framework" in International Conference on Conceptual Modeling, Springer, Cham, 2016, pp. 149-160, dx.doi.org/10.1007/978-3-030-05719-0

[4] The Standish Group, "CHAOS Report," The Standish Group, 2014.

[5] O. Sanchez, M. Terlizzi, "Cost and time project management success factors for information systems develop-ment projects, International Journal of Project Management vol. 35(8), 2017, pp. 1608-1626

[6] R. Nelson, "IT project management: Infamous failures, classic mistakes, and best practices, MIS Quarterly executive vol. 6(2), 2007

[7] International Institute of Business Analysis, "A Core Standard A Companion to A Guide to the Business Analysis Body of Knowledge (BABOK® Guide)" ver. 3, IIBA, 2017.

[8] ISO/IEC/IEEE, "Systems and software engineering - Life cycle processes - Requirements engineering", ISO/IEC/IEE, Standard 291482011, 2011, dx.doi.org/10.1109/ieeestd.2011.6146379

[9] Project Management Institute, "The PMI Guide to BUSINESS ANALYSIS", PMI,Newtown Square, Pennsylvania, 2017.

[10] K. Pohl, "Requirements engineering: fundamentals, principles, and techniques", Springer Publishing Company, 2010.

[11] S. Wagner, et al., "Status quo in requirements engineering: A theory and a global family of surveys", ACM Transactions on Software Engineering and Methodology (TOSEM), vol. 28(2), 2019, pp. 1-48.

[12] D. Fernandez, S. Wagner, "Naming the pain in requirements engineering: A design for a global family of surveys and first results from Germany", Information and Software Technology, vol. 57, 2015, pp. 616-643.

[13] O. Dieste , N. Juristo, "Systematic review and aggregation of empirical studies on elicitation techniques", IEEE Transactions on Software Engineering, vol. 37(2), 2011, pp. 283-304.

[14] L. Wong, et al., "A systematic literature review about software requirements elicitation", J Eng Sci Technol, vol. 12(2), 2017, pp. 296-317.

[15] C. Pacheco, I. Garcia, "A systematic literature review of stakeholder identification methods in requirements elicitation", J Syst Softw, vol. 85(9), 2012, pp. 2171-2181.

[16] T. Ambreen, et al. , "Empirical research in requirements engineering: trends and opportunities", Requirements Engineering, vol. 23(1), 2018 , pp. 63-95.

[17] H. Dar, et al. , "A systematic study on software requirements elicitation techniques and its challenges in mobile application development", IEEE Access, vol. 6, 2018, pp. 63859-63867.

[18] T. Lym, et al., "Elicitation Techniques for Internet of Things Applications Requirements: A Systematic Review", Proceedings of the 2018 VII International Conference on Network, Communication and Computing, 2018, pp. 182-188.

[19] F. Anwar, R. Razali, "A practical guide to requirements elicitation techniques selection-an empirical study", Middle-East Journal of Scientific Research, vol.11(8), 2011, pp. 1059-1067.

[20] D. Carrizo, et al., "Systematizing requirements elicitation technique selection", Information and Software Technology, vol.56(6), 2014, pp. 644669.

[21] L. Wong, D. Mauricio, "New Factors That Affect the Activities of the Requirements Elicitation Process", Journal of Engineering Science and Technology, vol.13(7), 2018, pp. 1992-2015.

[22] D. Paul, et al., "Business analysis", BCS, The Chartered Institute for IT, 2014.

[23] F. Yates, et al., "The Practice of Statistics", New York: W.H.Freeman, 1st ed., 1999.

[24] F. Yates, "Contingency table involving small numbers and the Chisquared test", Suppl J R Stat Soc, 1:217-35, 1934. 